\title{
Optimization and characterization of acrylonitrile/MAPE/ nano-clay bamboo nanocomposites by response surface methodology
}

\author{
Md.Rezaur Rahman ${ }^{1}$ (D) Muhammad Adamu ${ }^{1,2} \cdot$ Sinin Hamdan ${ }^{1}$. \\ Muhammad Khusairy Bin Bakri ${ }^{1} \cdot$ Fahmi Asyadi Bin Md. Yusof ${ }^{3}$. Afrasyab Khan ${ }^{4}$
}

Received: 1 September 2020 / Revised: 31 December 2020 / Accepted: 27 February 2021

(c) The Author(s), under exclusive licence to Springer-Verlag GmbH Germany, part of Springer Nature 2021

\begin{abstract}
Bamboo is abundantly and vastly available, which is known for its strength and verity of usage. In this work, the effect of acrylonitrile/MAPE/nano-clay on bamboo nanocomposites (BNCs) and its optimization were evaluated using response surface methodology (RSM). The developed BNCs were characterized by Fourier transform infrared spectroscopy (FTIR), X-ray diffraction (XRD), scanning electron microscope (SEM), thermogravimetry analysis (TGA) and differential scanning calorimetry (DSC) to study their compositional, morphological, and thermal properties. Based on the BNCs, the response surface models were developed to predict the modulus of elasticity (MOE) and modulus of rupture (MOR) of the BNCs. The developed models fitted the experimental values with $R^{2}$ close to 1 and residuals normal probability plot fitted to straight line. According to the models, the BNCs optimized values of MOE and MOR were higher compared to raw one. Scanning electron microscope (SEM) images showed that treatment on 8/12/60 BNC created a rough surface and eliminated hemicellulose on the surface of the bamboo, which improved the morphological properties, while XRD result on the 1/12/60 BNC showed an increase in the crystalline region than the amorphous region, which was due to the longer impregnation period. The melting and decomposition temperature of the BNCs had higher than the raw bamboo as indicated by TGA and DSC results. It is anticipated that the BNCs developed can compete against conventional hybrid nanomaterials with a great potential to be developed into eco-friendly nanocomposites used for interior and exterior construction application.
\end{abstract}

Keywords Bamboo $\cdot$ Acrylonitrile $\cdot$ Nano-clay $\cdot$ Malleated Polyethylene $\cdot$ Surface Response Methodology

Md.Rezaur Rahman

rmrezaur@unimas.my

Extended author information available on the last page of the article 